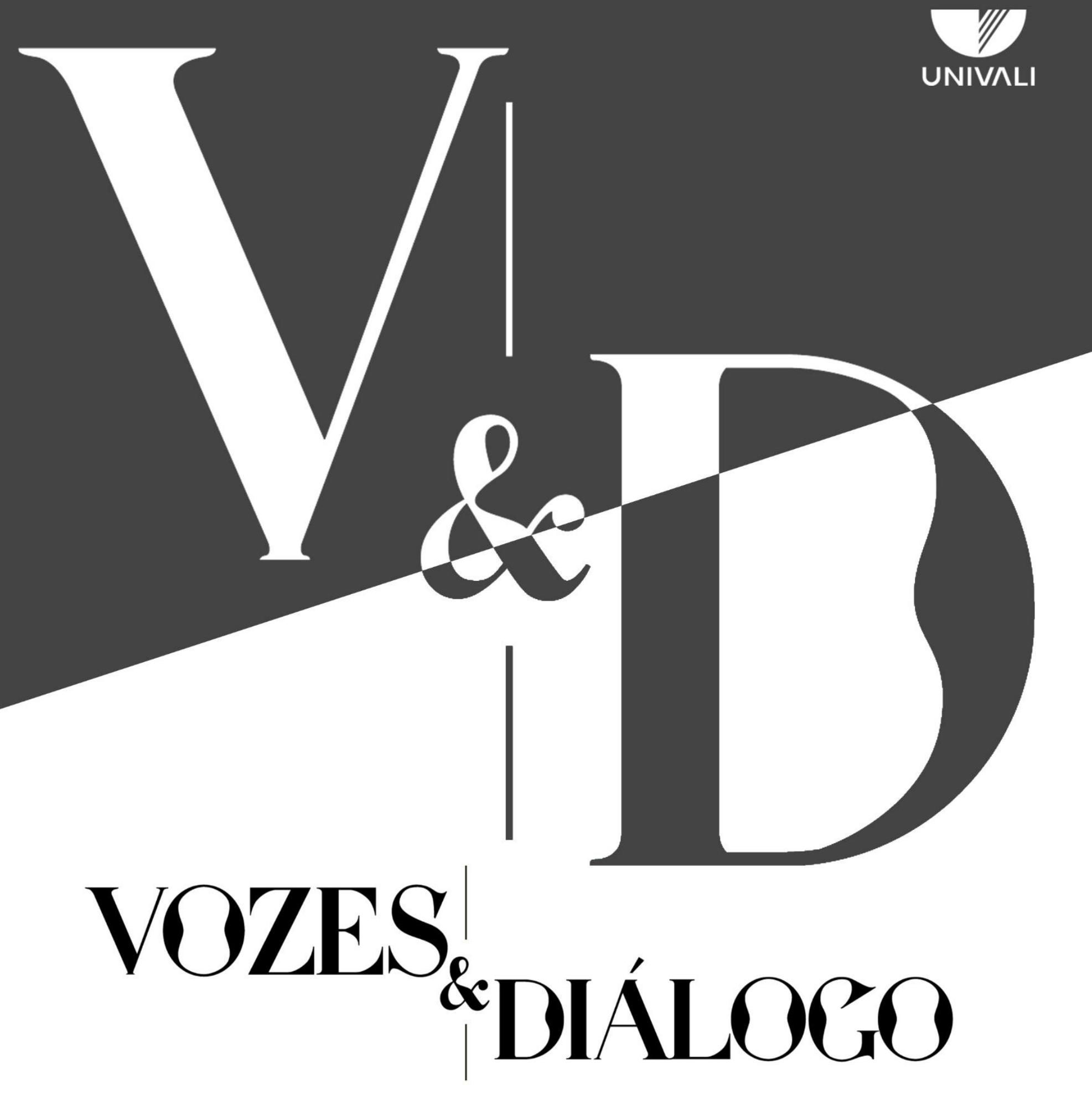

\title{
Comunicação em tempos de pandemia
}




\section{Editorial}

Há exatamente um ano, um vírus misterioso começava a assombrar o mundo a partir de uma província chinesa, embora já haja registros de que o SARS-Cov-2 tenha circulado por outras localidades do planeta antes do primeiro surto. Identificado no último dia do ano de 2019, o novo coronavírus passou a ser conhecido como causador da doença intitulada Covid-19 e começava a se alastrar rapidamente pela Ásia, Europa até chegar ao Brasil no início de março de 2020. Desde então, milhões de pessoas contraíram o vírus e, quando do fechamento desta edição, havia quase 74 milhões de infectados no mundo inteiro, quase 7 milhões somente no Brasil. Destes, quase 1,7 milhões de mortes, das quais 185 mil vítimas somente no Brasil.

Não é preciso dizer o quanto as relações interpessoais foram alteradas a partir da proliferação do vírus. Alterações sensíveis em todos os ramos da atividade humana, da saúde ao turismo, do esporte à ciência, da educação à comunicação. É justamente sobre os problemas oriundos deste último elemento que a Revista Vozes \& Diálogo trata no número 2 deste Volume 19.

"Comunicação em tempos de pandemia" tem o objetivo de trazer à tona textos que analisam os processos comunicativos durante a primeira pandemia do século XXI. Se as tecnologias da informação foram imprescindíveis para dar continuidade ao trabalho de informar a população, ainda mais em um momento de extrema tensão, as notícias falsas destinadas a causar pânico ou a desacreditar as autoridades de saúde precisaram ser combatidas pelos atores do processo, em tempo integral.

Os artigos criteriosamente e rigidamente selecionados pelos pareceristas desta edição trazem temas como telejornalismo e juventude em tempos de pandemia, ao enfocar a comunicação de interesse público; um debate sobre o discurso jornalístico e a política; necromídia e a estética da morte; a simulação do jornalismo em contexto de espalhamento de Fake News. Entre os artigos enviados em fluxo contínuo, destaque para um estudo aprofundado sobre o profissional de atendimento publicitário e uma resenha sobre os sentidos no gênero reportagem.

Mais uma vez, recebemos contribuições de todas as regiões brasileiras, com predominância das regiões Nordeste e Sudeste do Brasil. Dos 27 trabalhos recebidos para esta edição, sete artigos foram aprovados para publicação, o que corresponde a $26 \%$ do total de submissões. Agradecemos aos pesquisadores que submeteram seus trabalhos para a V\&D e, sobretudo, aos pareceristas que contribuíram para a seleção dos artigos aqui publicados. 
Desde já, convidamos os pesquisadores de todo o país a submeter seus artigos para o primeiro volume do ano de 2021 que tem previsão de publicação em junho. Desejamos a todos os nossos leitores, autores, avaliadores e integrantes do conselho editorial um novo ano repleto de realizações e que possa significar o término da pandemia do novo coronavírus.

Equipe Vozes e Diálogo 


\section{Vozes e Diálogo}

Volume 19 - número 02

Julho a Dezembro de 2020

\section{Editor}

Carlos Roberto Praxedes dos Santos - praxedes@univali.br

\section{Conselho Editorial}

Adriana Amaral - Unisinos

Adriana Tigre Lacerda Nilo - UFT

Álvaro Nunes Larangeira - Universidade Tuiuti do Paraná

Ana Cristina Spannenberg - Universidade Federal de Uberlândia

Débora Cristine Rocha - Pontifícia Universidade Católica de São Paulo;

Elson Faxina - Universidade Federal do Paraná - UFPR

Fabio Sadao Nakagawa - Universidade Federal da Bahia

Fernando Torres Andacht - Universidad de La República (Udelar), Uruguai

Fernando O. Paulino - UnB

Francisco Gilson Reboucas Porto Junior - UFT

Ivana Ebel - Derby University, Reino Unido

Laura Fernanda Cimino - Unifev

Magda Rodrigues da Cunha - Pontifícia Universidade Católica do Rio Grande do Sul

Manuel Pinto - Universidade do Minho - Campus de Gualtar, Portugal

Margarida Kunsch - USP

Merilyn Escobar de Oliveira - Universidade Paulista

Mônica Cristine Fort - Universidade Tuiuti do Paraná

Nelia Del Bianco - UnB

Rogério Christofoletti - UFSC

Rogerio Luiz Covaleski - UFPE

Rudimar Baldissera - UFRGS

Susana Herrera Damas - Universidad Carlos III de Madrid, Espanha

Yamila Heram - Universidad de Buenos Aires, Argentina 
Adriana Nilo - Aline Vaz - Álvaro Laranjeira - Andreia Santos - Antonio Cláudio Gonçalves - Carlos Golembiewski - Douglas Junio Assumpção - Fabiana Piccinin -Fabio Witzki - Geder Parzianello - Gustavo Paulo Zonta - Hélia Espinoza - Jhonatan Mata - Maria Carcará - Maria Clara Monteiro - Mayara Sataka - Paulo Silva Lins Cajazeira - Rodrigo dos Santos

\section{Projeto gráfico:}

Vinicius Batista de Oliveira

\section{Endereço para Correspondência:}

Rua Uruguai, 458 - Bloco C3 - sala 207

CEP 88302-202 Itajaí - SC

\section{Endereço Eletrônico:}

https://siaiap32.univali.br/seer/index.php/vd/index 


\section{Sumário}

Telejornalismo e juventude em tempos de pandemia: comunicação de interesse público

Discurso jornalístico e política em tempos de pandemia: um debate necessário

"Enquanto você lia este texto, mais um brasileiro morreu por causa do coronavírus". Pandemia, necromídia e estética da morte na Folha de S. Paulo.

A simulação do jornalismo em contexto de espalhamento de fake news

O saber-fazer do atendimento publicitário: as competências do profissional em atuação em São Borja, RS

"Deixei de sentir medo ao começar a te buscar": a memória e a poesia no documentário Elena

Resenha da obra "Referenciação e Ideologia: A Construção de Sentidos no Gênero Reportagem" 